Lubow, R. E., \& Moore, A. U. Latent inhibition: The effect of non-reinforced preexposure to the conditioned stimulus. Journal of Comparative \& Physiological Psychology, 1959, 52, 416-419.

Marchant, H. G., III, Mis, F. W., \& Moore, J. W. Conditioned inhibition of the rabbit's nictitating membrane response. Journal of Experimental Psychology, 1972, 95, 408-411.

Reiss, S., \& Wagner, A. R. CS habituation produces a "latent inhibition effect", but no active "conditioned inhibiton."
Learning \& Motivation, 1972, 3, 237-245.

Wagner, A. R \& Rescorla R. A. Inhibition in Pavlovian conditioning: application of a theory. In R. A. Boakes and M. S. Halliday (Eds.), Inhibition and learning. London: Academic Press, 1972.

(Received for publication August 29, 1974.)

\title{
Ordered recall of sounds and words in short-term memory*
}

\author{
EDWARD J. ROWE \\ Memorial University of Newfoundland, St. John's, Newfoundland, Canada
}

\begin{abstract}
Ordered recall of 7-item sequences of sounds and words was compared in two experiments. Bow-shaped serial position curves were found for both types of sequences, but more errors occurred with sounds at all serial positions. This inferior recall of sounds was independent of whether a verbal (Experiment I) or nonverbal (Experiment II) response procedure was used. The results confirm the superiority of verbal memory processes in the retention of order information.
\end{abstract}

Several recent experiments have demonstrated the importance of auditory-verbal memory processes in the retention of order information (e.g., del Castillo \& Gumenik, 1972; Paivio \& Csapo, 1969). These studies have compared serial recall or reconstruction of visual stimuli as a function of the availability of appropriate verbal labels, and have found better retention in cases where the items can be named by the Ss during presentation. Paivio (1971) interpreted such data to mean that the verbal memory code, being functionally linked to the auditory sensory modality, is specialized for retaining order informaton while the visual imagery code is not. This was advanced as one distinction between imagery and verbal processes.

A firmer case for this distinction can be made if the operation of verbal and nonverbal memory codes is contrasted independently of modality differences, e.g., if the comparison is restricted to the auditory modality alone. Philipchalk and Rowe (1971) reported an initial attempt in this direction. They compared retention of lists of short environmental sounds with their verbal labels in multitrial free and serial recall. Both kinds of items were recalled equally well in free recall but, in agreement with the hypothesized distinction between imagery and verbal processing modes, the words

*This researcn was supported by Grant A8580 from the National Reserach Council of Canada. Gordon Rowe and Madonna Tracey assisted in the data collection and analysis. Requests for reprints should be sent to the author at the Department of Psychology, Memorial University of New foundland, St. John's, Newfoundland, Canada A1C 5S7. consistently surpassed the sound across the five trials of serial recall. Even though the sounds could be named at presentation, it was assumed that the verbal code played a greater role in retention of the words, thus contributing to their more efficient serial ordering.

There were, however, certain difficulties inherent in the methodology of the Philipchalk and Rowe (1971) experiment which detract from an unambiguous interpretation of the results. For one thing, the interitem intervals were unequal for the sound and word lists, being $1 \mathrm{sec}$ for sounds but $5 \mathrm{sec}$ for words. This difference was unavoidable in constructing lists of comparable presentation rate, since the sounds averaged $5.4 \mathrm{sec}$, and the words $1 \mathrm{sec}$, in length. However, it is possible that the longer blank time between words facilitated their serial recall compared to sounds by allowing a greater opportunity for rehearsal of prior items within the list. Ss' proclivities toward rehearsal in memory tasks is well known, and cumulative rehearsal seems to be especially preferred as a strategy when ordered recall is required (Corballis, 1969). Given the positive influence of rehearsal on recall, the possible effect of different interitem intervals on the previous results cannot be discounted. The first experiment reported here was designed to remedy this shortcoming and provide a more stringent test of the difference between sounds and words in a serial recall task.

A further difficulty with the previous experiment involves the recall procedure. Recall was always verbal, i.e., the Ss wrote down the words or the names of the sounds, and the enhanced serial recall of the word lists 
might have been due at least partly to a greater ease of decoding the items into the verbal response mode. Experiment II of the present study used a nonverbal response procedure to offset any advantage accruing to the words from this factor.

\section{EXPERIMENT I}

\section{Method}

Subjects. The Ss were 20 undergraduates of Memorial University who were paid $\$ 2.00$ each for their participation. They were tested either individually or in groups of four or less.

Lists. The sounds consisted of segments of easily identifiable items taken from commercial sound effects recordings. Four items were selected from a set of 24 used in previous research (Rowe, Philipchalk, \& Cake, 1974). The four sounds and their presentation times were whip $(.4 \mathrm{sec})$, siren $(.7 \mathrm{sec})$, bell $(.7 \mathrm{sec})$, and telephone $(.6 \mathrm{sec})$. The shortened segments used in the present experiment consisted, as far as possible, of a discreet portion of the original sound (e.g., one crack of the whip, one telephone ring) which was still readily identified.

Sixteen 7 -item sequences were constructed by splicing individual copies of the sounds together on one tape, with a silent interval of approximately $.3 \mathrm{sec}$ between each. The overall length of each sequence was 7 sec. Each sequence contained one presentation of the four items and one repetition of three of the four. The repetitions were always separated by one or two other items and were about equally distributed throughout the seven serial positions. Across sequences, each item occurred in each serial position an equal number of times, and was used as a repetition equally often. The 16 sequences were duplicated to give a total of 32 , with each of the original 16 sequences being repeated in blocks of four. The order of blocks in the final version of the list was 12342314. Thus at least eight other sequences intervened between a given sequence and its repetition, which should be sufficient to obviate any effect of repetition on the recall scores (Melton, 1963). The word sequences consisted of the names of the sounds, recorded at a 1 -sec rate in a male voice. The order of items within and between sequences exactly paralleled that for the sounds.

Procedure. The experiment was conducted in a partially sound-deadened room with the lists presented through a loudspeaker. All Ss received both the sound and word lists, with half receiving the sounds first and half the words first. Both types of lists were preceded by two presentations of each item at a 5-sec rate, where the Ss wrote down the first letter of the name of each. This insured that the items could be identified correctly and, in the case of the sounds, to make sure that all Ss used the same words to name them. Twelve seconds were allowed for immediate recall of each sequence, with the Ss being instructed to write down the first letter of the name of each item in the correct order on a prepared answer sheet. They were told to begin their recall at the beginning of the list and to leave a blank if they were unable to remember the item in a given position. The recall interval ended with the recorded instruction "stop writing", followed after $2 \mathrm{sec}$ by the next sequence. A short rest period was given between presentation of the sound and word sets.

\section{Results and Discussion}

Items were scored as correct only if they were recalled in their correct serial position. The first eight sequences for both sounds and words served as practice trials and were not scored. The serial position error curves are shown in Fig. 1, where each mean is based on 480 observations ( 20 Ss by 24 sequences). The words were recalled better than the sounds at all serial positions, especially' toward the end of the list. An analysis of variance produced highly significant effects of list type $[\mathrm{F}(1,18)=116]$, serial position $[\mathrm{F}(6,108)=36.5]$, and the interaction between the two $[F(6,108)=9.02$; ps $<.001]$. Order of presentation of the sound and word sets was not significant as a main effect nor did it enter into any significant interactions. The List Type by Serial Position interaction reflects the fact that the difference between the curves is largest for terminal list positions. The difference between the two curves at each serial position was tested by a sign test, which showed significant differences $(p<.01)$ for all comparisons.

The sounds were clearly more difficult to recall in order than the words, especially in the recency portion of the curve. Informal observation of the Ss suggested that the sound sequences also took longer to recall than the words. This is probably the reason for tine reduced recency effect since a longer delay would have separated presentation and recall of items toward the end of the sequence. To see whether the sounds could be decoded correctly into the written response, eight additional Ss were tested on the same lists with instructions to write down the first letter of each item while tine sequences were being presented. The error rate across all serial positions averaged $6 \%$. Even assuming that the word sequences could be reproduced perfectly under such conditions $^{1}$, the slightly greater decoding difficulty for the sounds is obviously too small to account for the overall difference of $45 \%$ vs $22 \%$ obtained in the recall task. Nonetheless, the requirement that the sounds be translated into their verbal labels at retrieval does impose a disadvantage that does not apply to words. This problem is considered in Experiment II.

\section{EXPERIMENT II}

One obvious way of minimizing the difference in

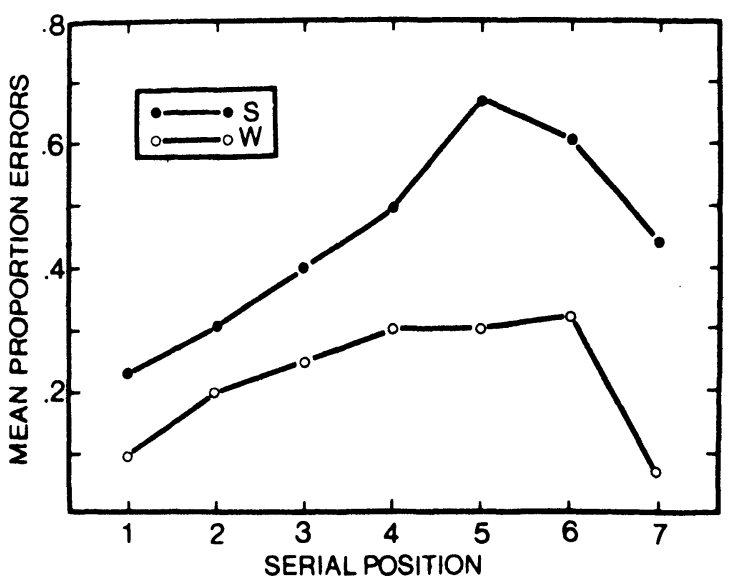

Fig. 1. Serial position curves for recall of sounds (S) and/words (W) in Experiment I. 


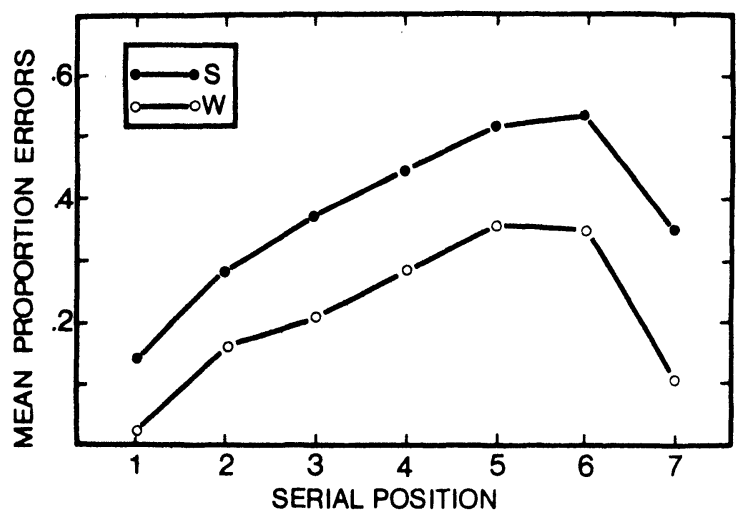

Fig. 2. Serial position curves for recall of sounds (S) and words (W) in Experiment II.

decoding difficulty between sounds and words would be to use a recognition procedure, for example, replaying an adjacent pair of items from the sequence in the same or a changed order. To maintain some procedural continuity with Experiment I, however, it was decided to adopt a variant of the recall paradigm for this experiment. The task used was serial reconstruction of the pictorial representations of the presented items. Since pictures as response terms require a decoding of both sounds and words before (or during) recall, any disadvantage resulting from the decoding requirement for sounds in the previous experiment should now apply to both types of items.

\section{Method}

Subjects. Sixteen paid undergraduates from Memorial University participated.

Procedure. The sequences and presentation procedure were the same as in Experiment I. The only change was the way in which the Ss recalled each sequence. Four line drawings were prepared by a professional artist, depicting the four items which made up the sequences. These were reduced on a photocopier and pasted on $2 \times 2$ cardboard squares. Two copies of each drawing were prepared in this way, and these were arranged in four piles in front of the $S$, with duplicate copies in each pile. As soon as a sequence ended the $S$ was allowed $12 \mathrm{sec}$ to place the drawings in a row corresponding to the order of presentation of the seven items, always starting at the beginning of the sequence. The $E$ then recorded the order, replaced the drawings in the four piles, and played the next sequence.

\section{Results and Discussion}

The results (Fig. 2) were similar to those of the first experiment. The sound sequences were harder to reconstruct than the words $[\mathrm{F}(1,15)=62.8]$, and the effect of serial position was significant $[F(6,90)=38.9$; ps <.001]. The difference between sounds and words was significant at the .01 level or better at serial positions 3 to 7 , and approached significance at Serial Position $1(p=.06)$ and $2(p=.08)$, as assessed by sign tests. The List Type by Serial Position interaction of Experiment I was not significant in this analysis, showing an equivalent recency effect for both sounds and words. Perhaps decoding sounds into pictures for recall is easier than sound-to-word decoding, so that the end items do not suffer as much from retrieval of earlier items.

Eight additional Ss performed the reconstruction task with both sets of sequences while they were being presented. The error rates were quite small: $3 \%$ for sounds and less than $1 \%$ for words. Thus, as expected, the nonverbal response requirement seems to largely eliminate any difference in decoding difficulty between sounds and words.

\section{GENERAL DISCUSSION}

The present data provide a clear confirmation of the superiority of words over sounds in sequential memory. The results converge with those of other investigators (e.g., del Castillo \& Gumelik, 1972; Paivio \& Csapo, 1969) in pointing to the salience of the verbal memory code in the retention of serial order. They furthermore extend this previous work by showing that the difference between verbal and nonverbal memory holds when the comparison is unconfounded with coding modality.

Why is the verbal code an efficient carrier of order information? Paivio (1971) has pointed to the fact that verbal coding processes are functionally tied to the auditory modality, which by definition must be able to deal with temporally ordered events. However, this cannot be the critical distinguishing feature of the verbal code which makes for efficient serial processing, since nonverbal sounds, which are presumably just as closely tied to audition, are much more difficult to order correctly. The advantage of the verbal code would seem to be related specifically to its speecil, rather than simply its auditory, characteristics. The problem thus becomes one of determining what it is about the representation of speech sounds that benefits retention of serial order. Recent research by Cole and Scott (1973) suggests that the transitions between vowels and consonants in the speech signal are especially important in this regard.

\section{REFERENCES}

Cole, R. A. \& Scott, B. Perception of temporal order in speech: The role of vowel transitions. Canadian Journal of Psychology, 1973, 27, 441-449.

Corballis, M. C. Patterns of rehearsal in immediate memory. British Journal of Psychology, 1969, 60, 41-49.

del Castillo, D. M., \& Gumenik, W. E. Sequential memory for familiar and unfamiliar forms. Journal of Experimental Psychology, 1972, 96, 90-96.

Melton, A. W. Implications of short-term memory for a general theory of memory. Journal of Verbal Learning and Verbal Behavior, 1963, 2, 1-21.

Paivio, A. Imagery and verbal processes. New York: Holt Rinehart \& Winston, 1971.

Paivio, A., \& Csapo, K. Concrete-image and verbal memory codes. Journal of Experimental Psychology, 1969, 80, 279-285.

Philipchalk, R. P., \& Rowe, E. J. Sequential and nonsequential memory for verbal and nonverbal auditory stimuli. Journal of Experimental Psychology, 1971, 91, 341-343.

Rowe, E. J., Philipchalk, R. P., \& Cake, L. J. Short-term memory for sounds and words. Journal of Experimental Psychology, $1974,102,1140-1142$.

\section{NOTE}

1. Unpublished data from a similar experiment suggest that this is in fact the case.

(R eceived for publication September 3, 1974.) 